\title{
Effects of Central Nervous System-Acting Drugs on Urinary Bladder Contraction in Unanesthetized Rats
}

\author{
Hitoshi KONTANI, Mikiko NAKAGAWA and Takeshi SAKAI \\ Department of Pharmacology. Hokuriku University, School of Pharmacy, \\ Kanagawa-machi, Kanazawa 920-11, Japan
}

Accepted April 6. 1989

\begin{abstract}
We studied the effects of drugs on urinary bladder contraction in unanesthetized $(\cup A)$ rats using the same method as that previously employed to investigate similar effects in urethane and $\alpha$-chloralose-anesthetized (A) rats. The surgical procedure was performed under halothane anesthesia, and after the recovery. the rats were restricted in a Ballman cage during the experiment. The pattern of the cystometrogram obtained in UA rats was very similar to that in A rats, and almost the same pattern was maintained for at least three hours. Baclofen $(10 \mathrm{mg} / \mathrm{kg}$. i.p.). morphine (10 mg/kg. i.p.) and pentobarbital $(20 \mathrm{mg} / \mathrm{kg}$. i.p.) completely inhibited the bladder contraction at doses only double those at which the same drugs inhibited the bladder contraction in A rats when i.v. injected. When the bladder pressure rose almost to the level of the peak pressure existing before injection of these drugs. the instilled solution leaked from the penis. On the other hand, even after injection of diazepam ( $5 \mathrm{mg} / \mathrm{kg}$, i.p.) at a dose five times greater than the minimum amount necessary for complete inhibition of bladder contraction in $A$ rats, the bladder contraction accompanying micturition continued in UA rats. It appears that the inhibitory effect of diazepam on bladder contraction in rats is potentiated by anesthesia.
\end{abstract}

Recently, the unanesthetized rat model has been developed for precise assessment of the micturition reflex and the effects of drugs on urinary bladder function, because general anesthetics act throughout the central nervous system and have been shown to affect urinary bladder function $(1,2)$. We have previously reported the inhibitory effects of diazepam, baclofen and morphine on the urinary bladder contraction accompanying micturition in rats anesthetized with urethane and $\alpha$-chloralose, and we found that the active sites of these drugs lie in the micturition centers of the brain stem and sacral cord (35). As Yaksh et al. (1) have reported that $\alpha$ chloralose has inhibitory effects on bladder function, it was thought that the two anesthetics used in our previous experiment would have influenced the inhibitory effects of the above drugs on urinary bladder contraction. In the present experiments, therefore, we studied the effects of these drugs on urinary bladder contraction in unanesthetized rats using the same method as that employed to study similar effects in anesthetized rats, and the results obtained from both experiments were compared.

\section{Materials and Methods}

We modified the experimental system described in the previous paper (5). Under halothane anesthesia, the bladder of male Wistar rats (weighing 250-350 g) was exposed via a midline incision in the abdomen, and a needle (1/4) attached to a silicone tube (O.D.. $1.0 \mathrm{~mm}$; I.D. $0.5 \mathrm{~mm}$; $30-40 \mathrm{~cm}$ in length) was inserted into the bladder through the left ureter. After ligation of the left ureter around the needle and insertion of another cannula for i.p. injection on the small intestine, the bladder was replaced in the abdominal cavity. and the incision was sutured. The urine from the left kidney flowed out from the incision of the ureter into the $a b$ - 
domen through which the needle was inserted. The right ureter was kept intact. The rat was then restrained in a Ballman cage (Natsume. Type III) and allowed to take water freely during the experiments. At least $4 \mathrm{hr}$ after the operation, bladder contraction was induced by infusion of Tyrode's solution lacking glucose into the bladder through the silicone tube at a constant rate (approximately $1 \mathrm{ml} / 10 \mathrm{~min}$ ), and the solution was continuously infused. The intravesical pressure signals measured by a pressure transducer (Nihon Kohden, LPU-0.1) connected to the silicone tube via a $\mathrm{T}$-tube were delivered by an amplifier (Nihon Kohden, RP-5) and recorded by a D.C. recorder (Watanabe Sokki. SR 6204). The amount of solution excreted from the penis was measured with a balance (Sartorius, PT 600).

Drugs used were: diazepam (Cercine ${ }^{\mathbb{B}}$ ) and morphine $\mathrm{HCl}$ (Takeda Chem. Ind., Ltd.). pentobarbital sodium (Nembutal ${ }^{(*)}$, Daiichi Seiyaku Co., Ltd.), and baclofen and naloxone $\mathrm{HCl}$ (gifts from Daiichi Seiyaku and Sankyo. respectively). Diazepam was directly injected with a syringe, and other drugs were injected via the cannula inserted for i.p. injection. The effect of each drug was examined in at least
4 rats. All drug concentrations in this report are expressed as those of each respective salt.

\section{Results}

1) Measurement procedures: Just after recovery from anesthesia, rats twisted their bodies in the Ballman cages for a while and then became quiet. When infusion of Tyrode's solution into the bladder was started and the bladder contraction accompanying micturition occurred, rats did not cry and hardly twitched their bodies. Although in a few rats, a small amount of blood was present in the excreted solution at the start of infusion, the solution became clear after two or three episodes of micturition. Throughout the experiment, the rats remained quiet.

About $30 \mathrm{~min}$ after infusion of the solution into the bladder was started, the pattern of the cystometrogram became constant or the interval of bladder contraction (micturition interval) was almost constant, and the mean time with the $S$.E. in seven rats was $8.1 \pm 0.5$ min. At almost constant level, the bladder began to contract, and the bladder pressure rose steeply (micturition threshold). The mean level of micturition threshold was $6.3 \pm$ $1.2 \mathrm{cmH}_{2} \mathrm{O}$. Each peak pressure during
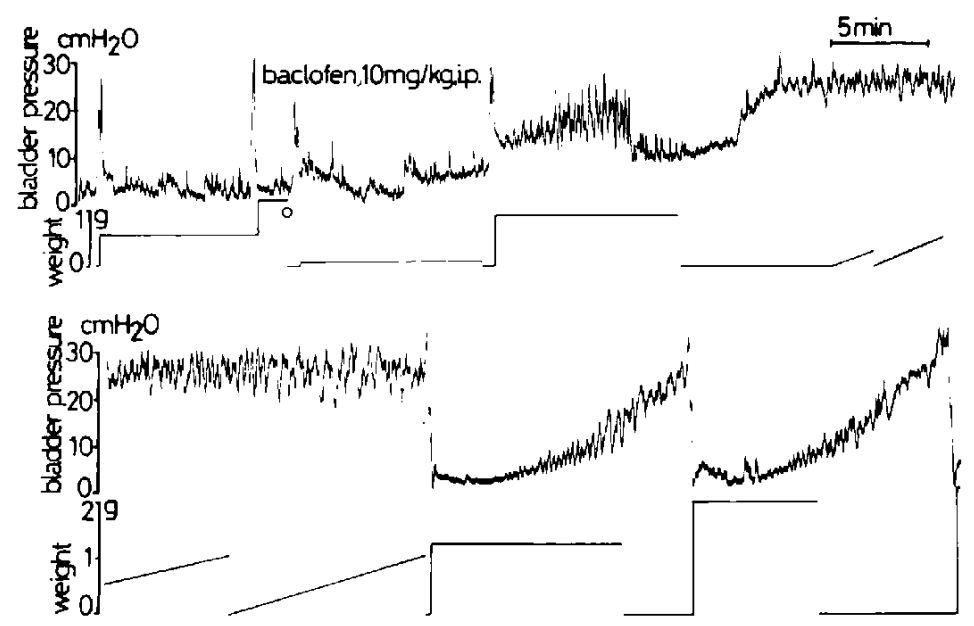

Fig. 1. The inhibitory effect of baclofen on urinary bladder contraction. Bladder contraction was induced by infusion of Tyrode's solution into the bladder. Vertical bar: bladder pressure $\left(\mathrm{cmH}_{2} \mathrm{O}\right)$ and weight $(\mathrm{g})$ of the solution excreted from the penis. The pair of traces indicate the cystometrogram and the amount of solution in the cap on a balance, respectively. The amount of solution is indicated for every $10 \mathrm{~min}$. The pair of traces in the lower part are continuous with the ends of the upper one. Open circle indicates injection of baclofen. 


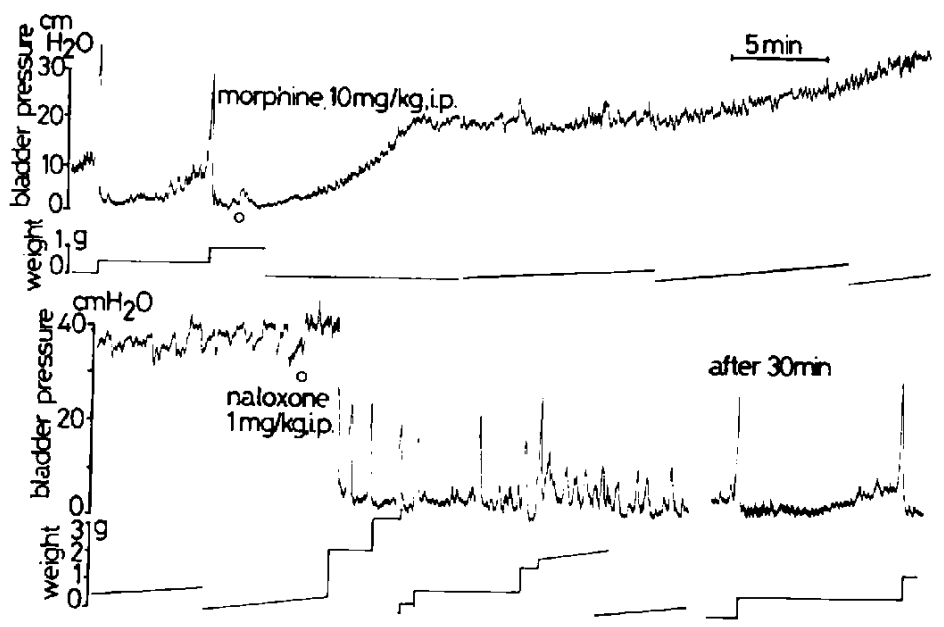

Fig. 2. The inhibitory effect of morphine on urinary bladder contraction in a conscious rat and the antagonistic effect of naloxone upon it. Bladder contraction was induced by infusion of Tyrode's solution into the bladder. For details, see the legend of Fig. 1. The pair of traces in the lower part are continuous with the ends of the upper one. Open circles indicate injection of morphine and naloxone.

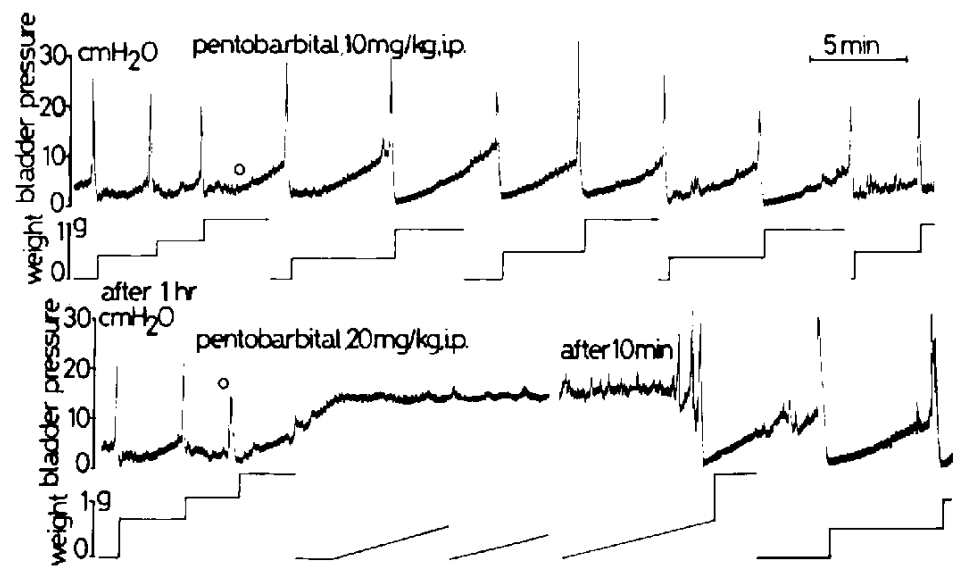

Fig. 3. The inhibitory effect of pentobarbital on urinary bladder contraction. Bladder contraction was induced by infusion of Tyrode's solution into the bladder. For details, see the legend of Fig. 1. There is a 1 -hr interval between the ends of the pair of traces in the upper part and the lower traces. Open circle indicates injection of pentobarbital.

bladder contraction was almost at a constant level, and the mean level was $24.1 \pm 3.5$ $\mathrm{cmH}_{2} \mathrm{O}$. The values of the three micturition parameters, i.e., micturition interval, micturition threshold and peak pressure during bladder contraction at about 60,120 and 180 min after the first measurement were not significantly different from the initial values. Therefore, drugs were injected after similar patterns had appeared on the cystometrogram.
2) Effects of drugs on bladder contraction: Figures 1-3 show the typical patterns of inhibitory effects of baclofen, morphine and pentobarbital, respectively. Baclofen $(10 \mathrm{mg} /$ kg. i.p.) completely inhibited the bladder contraction in three out of four rats or elevated the micturition threshold almost to the level at which instilled solution was excreted in another rat. Morphine $(10 \mathrm{mg} / \mathrm{kg}$, i.p.) completely inhibited the bladder contraction. As 
infusion of the solution into the bladder continued after the inhibition of bladder contraction by morphine, the bladder pressure rose to the level at which solution leaked from the penis. The percentage mean value of the bladder pressure at which solution leaked relative to the peak pressure before morphine injection was $127.3 \pm 46.0$ (mean \pm S.E., $n=4$ ), and in only two out of four rats, the pressure exceeded the peak pressure before injection of the drug. Naloxone (1 mg/ kg. i.p.) completely reversed the inhibitory effects of morphine $(10 \mathrm{mg} / \mathrm{kg}$, i.p.). Pentobarbital $(10 \mathrm{mg} / \mathrm{kg})$ caused a significant increase in the micturition threshold and prolongation of the micturition interval (Table 1) within $30 \mathrm{~min}$. Furthermore, addition of pentobarbital $(20 \mathrm{mg} / \mathrm{kg}) 2 \mathrm{hr}$ after its injection $(10 \mathrm{mg} / \mathrm{kg})$ completely inhibited bladder contraction in three out of five rats.

Table 1. Effects of pentobarbital and diazepam on the cystometrogram induced by infusion of Tyrode's solution into the bladder in unanesthetized rats

\begin{tabular}{|c|c|c|c|c|c|c|c|c|c|}
\hline \multirow{2}{*}{-} & \multicolumn{3}{|c|}{$\begin{array}{l}\text { before injection of } \\
\text { pentobarbital }(10 \mathrm{mg} / \mathrm{kg} \text {, i.p.) } \\
\quad(n=5)\end{array}$} & \multicolumn{3}{|c|}{$\begin{array}{l}\text { about } 15 \text { min after } \\
\text { injection }\end{array}$} & \multicolumn{3}{|c|}{$\begin{array}{l}\text { about } 30 \mathrm{~min} \text { after } \\
\text { injection }\end{array}$} \\
\hline & INT & $T P$ & $\mathrm{PP}$ & INT & TP & PP & INT & $\mathrm{TP}$ & PP \\
\hline mean & 3.2 & 4.4 & 27.0 & $5.6^{* *}$ & $9.9^{* *}$ & 32.4 & 4.1 & 5.2 & 28.6 \\
\hline \multirow[t]{2}{*}{ S.E. } & 0.5 & 0.9 & 6.4 & 0.3 & 1.8 & 3.0 & 0.5 & 0.5 & 9.4 \\
\hline & \multicolumn{3}{|c|}{$\begin{array}{l}\text { before injection of } \\
\text { diazepam }(5 \mathrm{mg} / \mathrm{kg} \text {. i.p.) } \\
\qquad(n=4)\end{array}$} & \multicolumn{3}{|c|}{$\begin{array}{l}\text { about } 30 \text { min after } \\
\text { injection }\end{array}$} & \multicolumn{3}{|c|}{$\begin{array}{l}\text { about } 90 \mathrm{~min} \text { after } \\
\text { injection }\end{array}$} \\
\hline & INT & $\mathrm{TP}$ & $\mathrm{PP}$ & INT & $\mathrm{TP}$ & PP & INT & TP & $P P$ \\
\hline mean & 6.4 & 5.5 & 26.0 & $10.3^{*}$ & 6.3 & 25.2 & $10.5^{*}$ & 7.8 & 21.2 \\
\hline S.E. & 0.5 & 1.0 & 3.7 & 2.0 & 1.2 & 2.0 & 0.8 & 0.6 & 2.2 \\
\hline
\end{tabular}

INT, micturition interval (min): TP, micturition threshold pressure $\left(\mathrm{cmH}_{2} \mathrm{O}\right)$; PP. peak pressure during bladder contraction $\left(\mathrm{cmH}_{2} \mathrm{O}\right)$. * or ** indicates $\mathrm{P}<0.05$ or $\mathrm{P}<0.01$, when compared with the value before drug injection, respectively.

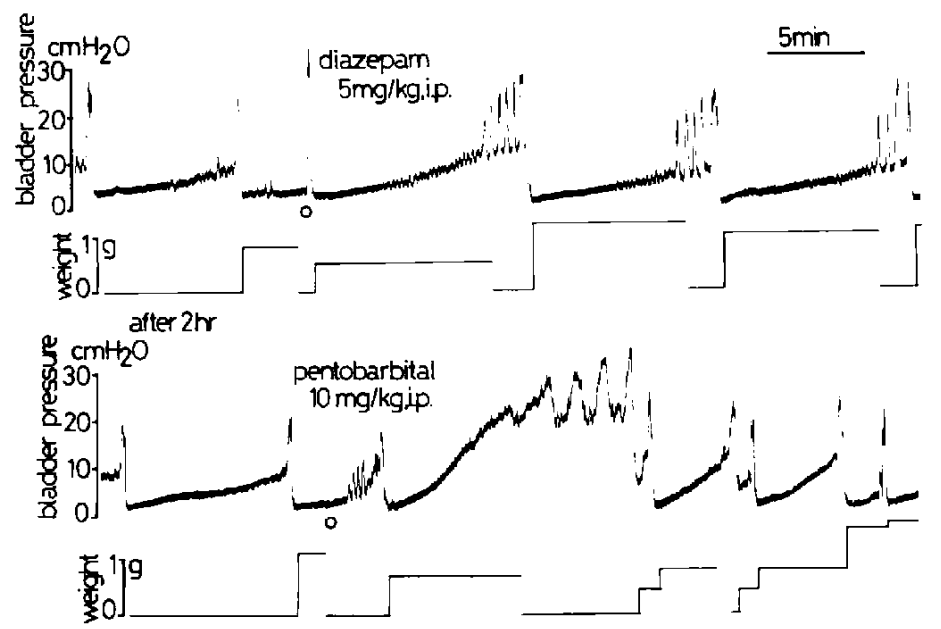

Fig. 4. The inhibitory effect of diazepam and a combination of diazepam and pentobarbital on urinary bladder contraction. Bladder contraction was induced by infusion of Tyrode's solution into the bladder. For details, see the legend of Fig. 1. There is a 2-hr interval between the ends of the pair of traces in the upper part and the lower traces. Open circles indicate injection of diazepam and pentobarbital. 
although the rats were not anesthetized by it. In two other rats, more marked elevation of the micturition threshold and prolongation of the micturition interval in comparison with those induced by pentobarbital ( $10 \mathrm{mg} / \mathrm{kg}$ ) appeared. After the inhibition of bladder contraction by these drugs, the bladder pressure rose almost to the level of the peak pressure existing before injection of these drugs, and the instilled solution leaked from the penis. On the other hand, diazepam ( $5 \mathrm{mg} / \mathrm{kg}$ ) prolonged the micturition interval, but did not interrupt micturition (Table 1). The inhibitory effect of diazepam continued $2 \mathrm{hr}$ after its injection and then addition of pentobarbital (10 $\mathrm{mg} / \mathrm{kg}$ ) interrupted the bladder contraction (Fig. 4).

\section{Discussion}

We modified our original method which had been used to study the effects of drugs on bladder contraction in anesthetized rats in order to study the corresponding effects in unanesthetized rats. The values of the micturition threshold and peak pressure during bladder contraction were almost the same in both anesthetized and unanesthetized rats (5). Although the rate of infusion of solution into the bladder in unanesthetized rats was higher than that in anesthetized rats, the micturition interval obtained in unanesthetized rats was comparatively long. In unanesthetized rats, baclofen, morphine and pentobarbital also completely inhibited the bladder contraction at doses approximately double those at which the same drugs inhibited the bladder contraction in anesthetized rats when i.v.injected (4. 5, for pentobarbital: our unpublished data). As there was no essential difference in the inhibitory effects of these drugs between the two groups of rats (Figs. $1-3$ and refs. $3-5$ ), it was considered that the inhibitory effects of these drugs on the micturition centers in the central nervous were not significantly potentiated by urethane or $\alpha$-chloralose. In anesthetized rats, morphine did not always increase the tone of the bladder outlet in rats at a dose range that completely inhibited the bladder contraction (5). and the same result was obtained in unanesthetized rats. The effects of morphine on the bladder outlet would not be affected by anesthesia. On the other hand, in unanesthetized rats, the bladder contraction could not be inhibited by diazepam at a dose five times greater than that which completely inhibited the bladder contraction in anesthetized rats (4). Pentobarbital (10 $\mathrm{mg} / \mathrm{kg}$ ) potentiated the inhibitory effects of diazepam on the bladder function (Fig. 4). It is wellknown that the inhibitory effects of benzodiazepine derivatives on the central nervous systems are potentiated by barbiturates and other central nervous depressants (6). The inhibitory effects of diazepam on the bladder function through the micturition center was found to be potentiated by general anesthesia. Pentobarbital (10 and $20 \mathrm{mg} / \mathrm{kg}$ ) exerted the inhibitory effects on the bladder motility in a dose-dependent manner, and pentobarbital $(20 \mathrm{mg} / \mathrm{kg}$ ) which did not anesthetize the rats completely inhibited the bladder contraction. The inhibitory effects of pentobarbital on the bladder motility did not result from anesthesia. The cystometrogram patterns after injection of diazepam or pentobarbital differed from each other (Figs. 3 and 4 ). It is thought that the sites of action of diazepam and pentobarbital related to the inhibition of bladder motility are different.

In conclusion, although precise experiments for studying the sites of action of drugs must be performed in anesthetized rats, there are drugs whose modes of action on bladder motility are different between anesthetized and unanesthetized rats; and therefore, the effects of drugs must be studied in unanesthetized rats as well. The afferent stimuli from the sensory endings in the bladder wall play an important role in the micturition reflex. In the present experiments, there was no difficulty in the insertion of the cannula into the bladder, and no injury to the bladder dome. which were reported by Yaksh et al. (1). occurred after chronic cannulation of the bladder. The present system is thought to be a useful one for studying the effects of drugs on bladder motility and the micturition reflex in unanesthetized rats.

\section{References}

1 Yaksh, T.L., Durant, P.A.C. and Brent, C.R.: Micturition in rat: a chronic model for study of bladder function and effect of anesthetics. Am. 
J. Physiol. 251, R1177-R1185 (1986)

2 Conte, B., D'Aranno, V., Santicioli, P., Giuliani, S., Mancinelli, A., Furio, M., Maggi, C.A. and Meli, A.: New model for recording cystometrograms in conscious, freely moving rats. $J$. Pharmacol. Meth. 18, 1-5 (1987)

3 Kontani, H., Kawabata, $Y$. and Koshiura, R.: In vivo effects of $\gamma$-aminobutyric acid on the urinary bladder contraction accompanying micturition. Japan. J. Pharmacol. 45, 45-53 (1987)

4 Kontani, H., Kawabata, Y. and Koshiura, R.: The effect of baclofen on the urinary bladder contraction accompanying micturition in anesthetized rats. Japan. J. Pharmacol. 46, 7-15 (1988)

5 Kontani, H. and Kawabata, Y.: A study of morphine-induced urinary retention in anesthetized rats capable of micturition. Japan. J. Pharmacol. 48, 31-36 (1988)

6 Jerram, T.: Hypnotics and sedatives. (Section editor: Blackwel!, B.) In Meyler's Side Effects of Drugs, Eleventh Edition. Edited by Dukes, M.N.G., p. 90-104, Elsevier, Amsterdam (1988) 